\title{
A Double-Blind Comparison of Orally Administered Ciramadol and Codeine for Relief of Postoperative Pain
}

\author{
David F. Graf, MD, Sujit K. Pandit, MD, Sarla P. Kothary, MBBS, DA, \\ and George R. Freeland, MD
}

\begin{abstract}
Ciramadol, a new analgesic with mixed narcotic agonist-antagonist actions, was compared with codeine and placebo in a double-blind study in 343 patients with postoperative pain. The patients received a single oral dose of either 30 or $60 \mathrm{mg}$ of ciramadol, $60 \mathrm{mg}$ of codeine, or placebo. As indicated by three efficacy measures (verbal and visual analog pain scores and pain relief scores), the three active treatments were superior to placebo in relieving pain, and 30 and $60 \mathrm{mg}$ of ciramadol generally were equivalent and superior, respectively, to $60 \mathrm{mg}$ of codeine. The group who took $60 \mathrm{mg}$ of ciramadol had a significantly $(\mathrm{P}<.05)$ lower cumulative remedication frequency than that for the other three groups and the highest proportion of satisfactory evaluations by patients and physicians. There was no statistically significant difference in the incidence of side effects (4\% to $11 \%$ ) among the treatment groups. Demonstrated safety and efficacy suggest a role for ciramadol in the treatment of postoperative pain.
\end{abstract}

C

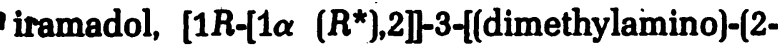
hydroxycyclohexyl)methylphenol, is an analgesic with the pharmacologic profile of a mixed narcotic agonist-antagonist. ${ }^{1}$ It has been shown to be an effective analgesic in rodents and primates when administered subcutaneously, intraperitoneally, orally, and intramuscularly. In human subjects, orally administered ciramadol is rapidly absorbed, with plasma levels reaching a maximum concentration between one and two hours after drug administration. Its elimination half-life is four to five hours. ${ }^{2}$

Clinical studies have shown that in oral doses of 20 and $60 \mathrm{mg}$, ciramadol was effective in the treatment of chronic pain due to cancer, ${ }^{3,4}$ and the analgesic effect was dose dependent and superior to that of placebo. ${ }^{4}$ Single oral doses of $\mathbf{3 0}$ and $\mathbf{9 0} \mathrm{mg}$ of ciramadol also were superior to $60 \mathrm{mg}$ of codeine for relief of

From the Department of Anesthesiology, University of West Virginia, Morgantown, WV (Dr. Graf); the Department of Anesthesiology, University of Michigan Medical Center, Ann Arbor, MI (Drs. Pandit and Kothary); and Wyeth Laboratories, Philadelphia, PA (Dr. Freeland). This study was supported by grants from Wyeth Laboratories. All study drugs were provided by Wyeth Laboratories. Address for reprints: George R. Freeland, MD, Wyeth Laborätories, PO Box 8299, Philadelphia, PA 19101. moderate to severe cancer pain. ${ }^{5}$ Ciramadol has been found to be safe and effective in the treatment of postepisiotomy and postoperative pain in oral doses of 15 to $60 \mathrm{mg} .{ }^{6-8}$ Ciramadol $60 \mathrm{mg}$ provided relief of postoperative pain that was superior and longer lasting than that provided by $50 \mathrm{mg}$ of pentazocine. ${ }^{8}$ In the treatment of moderate and severe postepisiotomy pain, $15 \mathrm{mg}, 30 \mathrm{mg}$, and $60 \mathrm{mg}$ of ciramadol were superior to placebo and to $60 \mathrm{mg}$ of codeine in producing analgesia for up to six hours. ${ }^{7}$ Ciramadol and codeine, however, have not been compared in the treatment of postoperative pain.

The present study was designed to compare two oral doses of ciramadol with codeine and a placebo in patients with moderate or severe postoperative pain.

\section{METHODS}

Patients of either sex, any race, and physical status I or II, as defined by the American Society of Anesthesiologists, ${ }^{9}$ who were experiencing moderate to severe postoperative pain for which the attending surgeon had ordered oral analgesics, were eligible for inclusion in the study. They had to be between the ages of 18 and 65 years and weigh between 100 and $210 \mathrm{lb}$. Those who had a history of chronic analgesic or 
tranquilizer use or known drug dependence, were sensitive to narcotics or narcotic antagonists; were taking interfering or potentially interacting medications, had received an analgesic within three hours of the start of the study, or were unable to communicate meaningful information about their pain were excluded. Pregnant women also were excluded. Institutional review board approval was granted, and written informed consent was obtained from each patient before surgery.

The six-hour study was conducted at separate sites by two trained medical investigators using a common protocol. The study was double blind; patients were assigned randomly to one of four treatment groups and received a single oral tablet containing either 30 $\mathrm{mg}$ of ciramadol, $60 \mathrm{mg}$ of ciramadol, $60 \mathrm{mg}$ of codeine, or placebo. All study drugs were identical in appearance and were administered between three and 48 hours after surgery. Efficacy and safety assessments of the test medications were made immediately before drug administration (baseline) and at 30 minutes and 1, 2, 3, 4, 5, and 6 hours after administration.

Three scales were used during the study to record the patients' subjective evaluations of drug efficacy at each observation time. Pain intensity was rated verbally as none (0), mild (1), moderate (2), or severe (3). The patients also rated their pain intensity on a visual scale, consisting of a $100-\mathrm{mm}$ line with one end representing no pain and the other representing worst pain ever felt. Measurement of each patient's mark on the line resulted in a pain analog intensity score between zero and 100 . Pain relief was assessed as worse pain $(-1)$, no relief $(0)$, a little relief $(1)$, moderate relief (2), a lot of relief (3), or complete relief (4).

Several measures of analgesic efficacy were derived from the pain intensity and relief scores. Pain intensity differences (PIDs) and pain analog intensity differences (PAIDs) were calculated by subtracting the respective pain intensity score at each observation time from the baseline intensity score. Furthermore, the weighted PID and PAID scores for each patient at each evaluation (i.e., each score multiplied by the fraction of an hour since the last observation) were added to obtain the summed pain intensity difference (SPID) and the summed pain analog intensity difference (SPAID), respectively. Total pain relief (TOTPAR) scores were obtained by adding the weighted pain relief scores at each evaluation (i.e., each score multiplied by the fraction of an hour since the last observation).
At each observation time, patients who required additional analgesic medication were withdrawn from the study and given standard analgesic medication. According to the protocol advocated by Lasagna $^{10}$ and Houde and associates, ${ }^{11}$ these patients were assigned efficacy scores corresponding to baseline pain intensity or to no relief after they were given additional medication.

The degree of sedation was rated by the investigator at each observation time as none, mild, moderate, or marked. Vital signs were recorded at each observation time. All adverse experiences reported by the patients or observed by the investigator were recorded and rated by the investigator as definitely, probably, possibly, or not related to the drug treatment.

At the end of the six-hour study period, patients were asked to rate their overall drug experience as excellent, good, fair, or poor. The investigator also rated each patient's overall response to the study drug as satisfactory or unsatisfactory, after reviewing the onset and duration of analgesia and the presence or absence of adverse effects.

The demographic variables of a continuous nature were compared among the groups by a one-way analysis of variance, supplemented by the StudentNewman-Keuls test for pairwise comparisons. ${ }^{12}$ Categorized baseline assessments and the frequencies of adverse effects were compared among the treatment groups, using the chi-square test supplemented by Fisher's exact test for pairwise comparisons when appropriate. Efficacy variables of an ordinal or nominal nature were analyzed by the generalized Cochran-Mantel-Haenszel approach using marginal ridit scores with baseline scores and investigator as covariables. ${ }^{13}$ Comparison of the PAID scores and vital signs among treatment groups were made using an analysis of covariance. The absence of statistically significant investigator-by-therapy interactions was verified by a two-way model. Changes within groups in vital signs were analyzed with a paired $t$ test.

\section{RESULTS}

\section{Patient Population}

The study population included 343 patients: 83 received $30 \mathrm{mg}$ of ciramadol, 87 received $60 \mathrm{mg}$ of ciramadol, 84 received $60 \mathrm{mg}$ of codeine, and 89 received a placebo. Of the total patient population, 203 (59\%) were men, $323(94 \%)$ were white, $18(5 \%)$ were black, and two (1\%) were of other races. Age 
ranged from 18 to 65 years (mean age, 36 years) and weight ranged from 91 to $253 \mathrm{lb}$ (mean weight, $160 \mathrm{lb}$ ). Initial pain intensity was moderate for 224 patients (65\%) and severe for 119 patients (35\%). Statistical analysis revealed no significant differences among the treatment groups with respect to demographic characteristics and initial pain intensity. Thus, subsequent analyses included data from all patients in each treatment group regardless of initial pain intensity.

Pooling of the data collected at the two study sites seemed justified because each investigator used identical procedures for patient admission and assignment to treatment groups, drug administration, and observation, as well as identical criteria for efficacy and safety evaluation. Moreover, no major inconsistencies were found in the results obtained at the two investigational sites, nor were there any statistically significant effects for investigator or investigator-by-therapy interactions. Thus, the study results represent pooled data from the two populations.

Twenty-seven patients were excluded from the efficacy evaluation, 23 because they did not fulfill the inclusion criteria and four because they vomited within $\mathbf{3 0}$ minutes of receiving the test drug. Two of the 27 patients were sedated heavily at the time of drug administration and also were excluded from the sedation analysis, and one patient was a class III surgical risk and thus was excluded from both the sedation and vital signs analyses. The patients evaluated for efficacy were comparable statistically to the total study group. All patients were included in the safety evaluation.

\section{Efficacy Evaluations}

Throlighout the six-hour observation period, consistently higher mean scores, indicating greater pain relief, were noted for the three active therapy groups as compared with those for the placebo group. Statistically significant advantages over placebo in the PID (not shown) and PAID scores (Table) as well as the pain relief scores (Figure 1) were observed for the $\mathbf{6 0}$ mg ciramadol group at one through six hours, for the $30 \mathrm{mg}$ ciramadol group at two through five hours, and for the codeine group at one through four hours. In general, scores in the $60 \mathrm{mg}$ ciramadol group tended to be higher than those in the $30 \mathrm{mg}$ ciramadol and the $60 \mathrm{mg}$ codeine groups. Efficacy scores for the $30 \mathrm{mg}$ ciramadol group and the $\mathbf{6 0} \mathrm{mg}$ codeine group generally were similar with a slight advantage for the codeine group during the first hour and for the $30 \mathrm{mg}$
TABLE

\begin{tabular}{|c|c|c|c|c|}
\hline Time & $\begin{array}{c}\text { Ciramadol } \\
\mathbf{3 0} \mathbf{~ m g}\end{array}$ & $\begin{array}{c}\text { Ciramadol } \\
60 \mathrm{mg}\end{array}$ & $\begin{array}{c}\text { Codeine } \\
60 \mathrm{mg}\end{array}$ & Placebo \\
\hline $\begin{array}{l}30 \mathrm{~min} \\
1 \mathrm{hr} \\
2 \mathrm{hr} \\
3 \mathrm{hr} \\
4 \mathrm{hr} \\
5 \mathrm{hr} \\
6 \mathrm{hr}\end{array}$ & $\begin{array}{l}12.3 \pm 2.3 \\
18.7 \pm 2.6 \\
20.3 \dagger \pm 2.8 \\
18.6 t \pm 3.0 \\
17.2 t \pm 2.8 \\
15.6 t \pm 2.6 \\
13.8 \pm 2.6\end{array}$ & $\begin{array}{l}17.5 \pm 2.4 \\
21.8 \dagger \pm 3.0 \\
24.2 \dagger \pm 2.8 \\
24.3 t \pm 3.1 \\
22.6 \dagger \pm 2.9 \\
20.7 \dagger \pm 2.9 \\
19.6 t \pm 2.9\end{array}$ & $\begin{array}{l}16.4 \pm 2.5 \\
23.7 \dagger \pm 2.7 \\
19.9 \dagger \pm 3.1 \\
17.8 \dagger \pm 2.9 \\
17.1 \dagger \pm 2.8 \\
14.2 \pm 2.7 \\
12.4 \pm 2.6\end{array}$ & $\begin{array}{r}11.5 \pm 2.3 \\
12.3 \pm 2.7 \\
9.0 \pm 2.7 \\
8.6 \pm 2.5 \\
8.2 \pm 2.4 \\
7.5 \pm 2.3 \\
7.1 \pm 2.2\end{array}$ \\
\hline
\end{tabular}

* Higher scores indicate greater pain relief. Data are presented as mean \pm standard error. of the mean.

tValue is significantly ( $P$ < .05) higher than placebo.

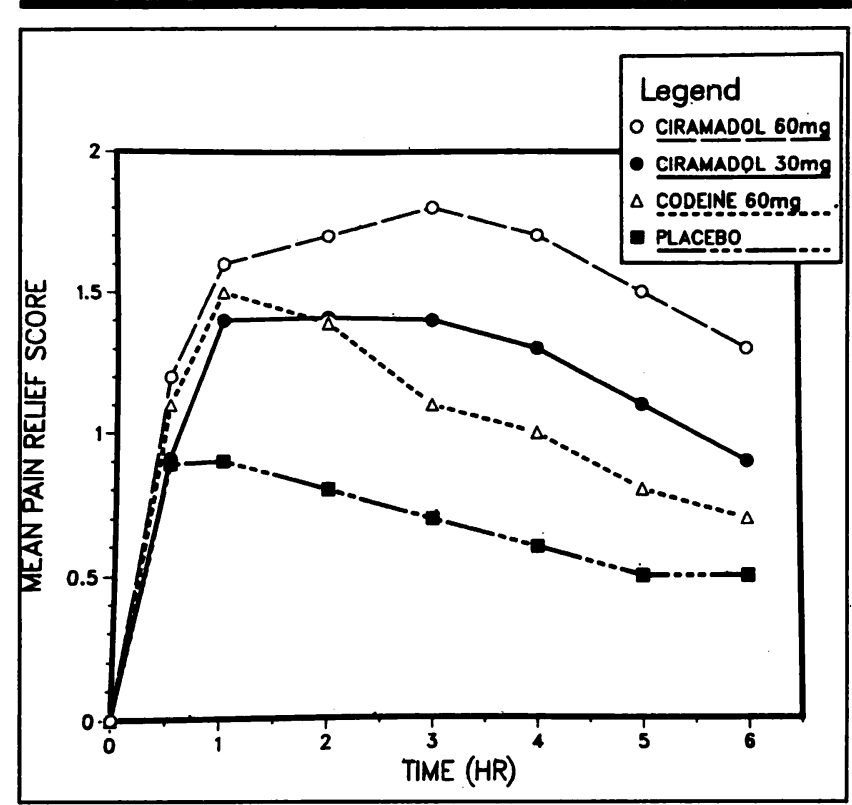

Figure 1. Mean pain relief scores for the four treatment groups during the six-hour observation period. Higher scores indicate greater pain relief.

ciramadol group at three through six hours. A statistical advantage was observed for the $60 \mathrm{mg}$ ciramadol group compared with the codeine group in pain relief scores at three through six hours and in PID scores at three, five, and six hours. Other pairwise differences in efficacy scores between active treatment groups were not statistically significant.

Effective pain relief, as measured by a pain relief score of moderate or greater, was reported at some time during the observation period by $65 \%$ of the patients treated with $30 \mathrm{mg}$ of ciramadol, $63 \%$ of those 


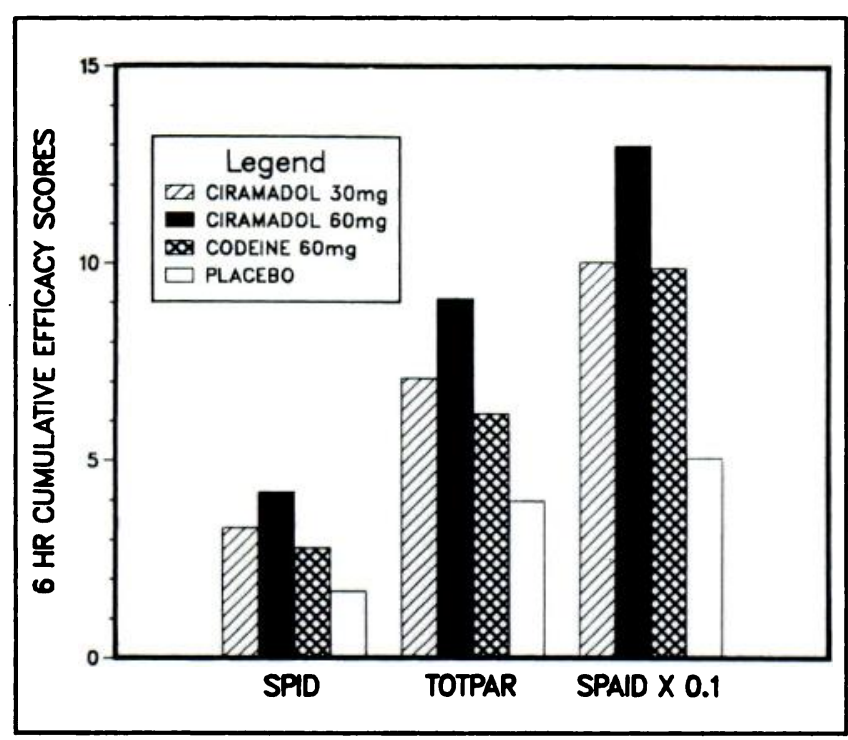

Figure 2. Cumulative pain scores for the six-hour observation period. Higher scores indicate greater pain relief. $S P I D=$ summed pain intensity difference; $T O T P A R=$ total pain relief; SPAID = summed pain analog intensity difference.

treated with $60 \mathrm{mg}$ of ciramadol, $61 \%$ of those treated with $60 \mathrm{mg}$ of codeine, and $47 \%$ of those treated with placebo. Significantly higher $(P<.05)$ proportions of patients in the $30 \mathrm{mg}$ ciramadol group between two and six hours, in the $60 \mathrm{mg}$ ciramadol group between one and six hours, and in the codeine group at one and two hours had effective pain relief than those in the placebo group. In addition, between three and six hours, the proportion of patients with effective relief was significantly higher $(P<.05)$ in the $60 \mathrm{mg}$ ciramadol group than in the codeine group.

The cumulative six-hour efficacy scores (SPID, TOTPAR, SPAID) were significantly higher $(P<.05)$ for the three active treatment groups than for the placebo group (Figure 2). The highest scores on all three scales were seen in the $60 \mathrm{mg}$ ciramadol group. Scores for the $30 \mathrm{mg}$ ciramadol group and the $60 \mathrm{mg}$ codeine group were generally similar, although slightly higher scores were reported for the $\mathbf{3 0} \mathrm{mg}$ ciramadol group.

At six hours, $55 \%$ of patients in the $30 \mathrm{mg}$ ciramadol group, $47 \%$ in the $60 \mathrm{mg}$ ciramadol group, $70 \%$ in the codeine group, and $79 \%$ in the placebo group had requested additional analgesic medication. The cumulative remedication rates for the $30 \mathrm{mg}$ and 60 mg ciramadol groups, but not the codeine group, were significantly lower $(P<.001)$ than that for the placebo group. At six hours, the remedication rates for the ciramadol groups were also significantly lower $(P<.05)$ than that for the codeine group.

\section{Safety Evaluation}

The majority of patients were either not sedated or only mildly sedated at baseline. Some increase in mean sedation level was seen in each group after drug administration, with slightly larger increases (to a mean level near mild) in the active treatment groups. There was no statistically significant difference in sedation scores among the active treatment groups at any time.

No statistically significant changes in systolic or diastolic blood pressure were noted within or among the treatment groups. Statistically significant decreases from the baseline pulse rate (by 1.7 to 2.1 beats/min) were observed in the $60 \mathrm{mg}$ ciramadol group at 30 minutes and one hour. Although mean respiratory rates were significantly lower $(P<.05)$ than baseline values at various observation times in all four treatment groups (by 0.8 to 1.3 respirations/ min), these changes were considered clinically unimportant. No clinically significant respiratory depression was observed.

Adverse experiences considered to be at least possibly drug related were reported by nine (11\%) patients in the $30 \mathrm{mg}$ ciramadol group, six (7\%) in the $60 \mathrm{mg}$ ciramadol group, three $(4 \%)$ in the $60 \mathrm{mg}$ codeine group, and five $(6 \%)$ in the placebo group. The most commonly reported adverse effects were nausea $(1 \%$ to $7 \%)$, vomiting (0\% to $6 \%)$, and dizziness $(0 \%$ to $3 \%)$. No statistically significant differences in the frequencies of adverse effects were noted among the four treatment groups.

\section{Overall Evaluations of Test Medications}

The physician rated the test medication as satisfactory for $52 \%$ of patients in the $30 \mathrm{mg}$ ciramadol group, $64 \%$ in the $60 \mathrm{mg}$ ciramadol group, $54 \%$ in the $60 \mathrm{mg}$ codeine group, and $31 \%$ in the placebo group. Overall ratings of good or excellent were given by $52 \%$ of patients treated with $30 \mathrm{mg}$ of ciramadol, $61 \%$ given $60 \mathrm{mg}$ of ciramadol, $51 \%$ treated with $60 \mathrm{mg}$ of codeine, and $23 \%$ of the placebo-treated patients. A significant $(P<.01)$ advantage over placebo was noted in both the physician and patient evaluations for 30 and $60 \mathrm{mg}$ of ciramadol and $60 \mathrm{mg}$ of codeine. 


\section{DISCUSSION}

The search for analgesic agents with efficacy similar to that of the narcotic agonists and reduced dependence liability has resulted in the development of the mixed narcotic agonist-antagonist analgesics. In this study, ciramadol, a new analgesic with a mixed agonist-antagonist profile, was superior to placebo for relief of moderate to severe postoperative pain. The analgesic effect observed in this study after ciramadol administration is consistent with the results of other ciramadol studies. ${ }^{4,6,8}$ Moreover, efficacy scores and overall evaluations were consistently higher for patients who received $60 \mathrm{mg}$ of ciramadol than for patients in the other three treatment groups; the scores and ratings for patients who received $30 \mathrm{mg}$ of ciramadol and $60 \mathrm{mg}$ of codeine generally were similar. Not only did the $60 \mathrm{mg}$ dose of ciramadol provide more effective pain relief than codeine for a greater proportion of patients, but both doses of ciramadol resulted in a longer duration of analgesia than did codeine, as indicated by significantly lower remedication rates and higher efficacy scores at later time periods. The duration of action for ciramadol observed in this study is consistent with a reported half-life of four to five hours. ${ }^{3}$

In addition to having an analgesic efficacy that was comparable to that of codeine and a duration of action that was longer than that of codeine, ciramadol administration was associated with a low incidence of mild side effects that was similar to that for codeine. The type, severity, and incidence of adverse effects observed among ciramadol-treated patients were similar to those reported from other clinical ciramadol studies. ${ }^{4,6,8}$ Of particular importance for postsurgical patients, there were no changes in respiratory rate and clinically significant respiratory depression among ciramadol- and codeine-treated patients.

It is interesting that these findings are not consistent with those of an earlier study in which intramuscularly administered ciramadol was reported not to be effective in relieving postoperative pain. ${ }^{14}$ The investigators attributed this to a predominance of the narcotic antagonist effect in patients with prior narcotic exposure. This explanation is plausible, particularly in reference to a population of patients who have received multiple doses of narcotic agonists. Furthermore, it suggests that prior exposure to narcotics is an important consideration in the patient's history for the effective use of mixed agonist-antagonist analgesics. In the present study, however, there were no explicit restrictions on the amount of narcotics that had been used, either intraoperatively or postoperatively, before patient enrollment. Indeed, almost every patient receiving ciramadol had been treated previously with a pure narcotic agonist, and nearly $50 \%$ of the patients in the ciramadol groups had received three or more doses of narcotics before enrollment. This suggests that the effective use of orally administered ciramadol is not limited to the treatment of patients who are entirely without previous narcotic exposure. The dissimilar results of the two studies could be due to differences in the dosages of previous narcotic agents, which would tend to be higher for patients who require parenteral analgesics, or to differences in the timing of prior narcotic administration relative to the subsequent administration of ciramadol.

This study has demonstrated the safety and efficacy of ciramadol for the treatment of moderate and severe postoperative pain. As measured by standard analgesia scales and overall evaluations, $30 \mathrm{mg}$ and $60 \mathrm{mg}$ of ciramadol were found to be equal and superior to 60 mg of codeine, respectively. A statistical advantage was found for ciramadol with respect to codeine at the later observation times, indicating a longer duration of analgesic effect.

The results of this study indicate that ciramadol is a promising analgesic for use in the treatment of moderate and severe postoperative pain and that further clinical investigation is warranted.

The authors wish to acknowledge G.S. Littman, $\mathrm{PhD}$, and his colleagues for statistical analyses and V.L. Pascucci, PharmD, for editorial assistance.

\section{REFERENCES}

1. Yardley JP, Fletcher H, Russell PB: A potent benzylamine analgesic: (-)cis-2-(alpha-dimethylamino-m-hydroxybenzyl)-cyclohexanol. Experientia 1978;34:1124-1125.

2. Locniskar A, Lasseter KC, Freeland GR, et al: Pharmacokinetics and bioavailability of ciramadol, a new analgesic. Clin Res 1983;31:630A.

3. Cochrane AD, Bell R, Sullivan JR, et al: Ciramadol: A new analgesic. Med J Aust 1979;2:501-502.

4. Staquet MJ: Analgesic effect of ciramadol in patients with chronic pain. Curr Med Res Opin 1980;6:475-477.

5. Stambaugh JE, McAdams J, Freeland G: Comparison of the analgesic efficacy and safety of oral ciramadol (Ciradol) to codeine and placebo in patients with chronic cancer pain. Clin Pharmacol Ther 1983;33:198.

6. Fragen RJ, Caldwell NJ: Comparison of three doses of oral ciramadol and placebo for the treatment of moderate to 
severe postoperative pain. I Clin Pharmacol 1982;22:459465.

7. Bloomfield SS, Sinksield A, Mitchell J et al: Ciramadol (Wy-15,705) and codeine analgesia after episiotomy, in Harris LS (ed): NIDA Research Monograph 43. Rockville, Maryland, Office of Science, NIDA 1982, pp 224-230.

8. Camu F: Double-blind comparison of the analgesic response to oral ciramadol $(\mathrm{Wy}-15,705)$ and pentazocine in postoperative pain. Eur J Clin Pharmacol 1981;19:259-262. 9. Owens WD, Felts JA, SpitznageI EL: ASA physical status classifications: A study of consistency of ratings. Anesthesiol 1978;49:239-243.

10. Lasagna L: The evaluation of analgesic compounds in patients suffering from postoperative pain, in Lasagna L (ed): International Encyclopedia of Pharmacology and
Therapeutics, section 6. New York, Pergamon Press, 1966, pp 51-58.

11. Houde RW, Wallenstein SL, Beaver WT: Evaluation of analgesics in patients with cancer pain, in Lasagna $\mathrm{L}$ (ed): International Encyclopedia of Pharmacology and Therapeutics, section 6. New York, Pergamon Press, 1966, pp 59-97.

12. Steel RGD, Torrie JH: Principles and Procedures of Statistics. New York, McGraw Hill Book Company, 1960.

13. Sokal RR, Rohlf F]: Biometry. San Francisco, W.H. Freeman, 1969.

14. Fragen RJ, Kouzmanoff C, Caldwell NJ: Intramuscularly administered ciramadol for management of postoperative pain: A comparative study. I Clin Pharmacol 1983;23:219226.

\section{Status Report From the Council on Clinical Pharmacology: November 1985}

Six years ago, duly appointed representatives of the American College of Clinical Pharmacology (ACCP), the American Society for Clinical Pharmacology and Therapeutics (ASCPT), and the American Society for Pharmacology and Experimental Therapeutics (ASPET) formed the Council on Clinical Pharmacology to explore the possibilities of seeking clinical board recognition of clinical pharmacology.

After intensive discussion and careful consideration of all available options, the Council on Clinical Pharmacology concluded that our first option would be to seek a "Certificate of Special Competency" in clinical pharmacology for those clinical pharmacologists who hold board certification in internal medicine from the American Board of Internal Medicine (ABIM) within the American Board of Medical Specialties.

On May 13, 1983 the Council on Clinical Pharmacology submitted to the ABIM a detailed request of a board certification in clinical pharmacology. The ABIM graciously acknowledged our application as carefully prepared-one that followed a thoughtful. informed approach. However, after additional correspondence and careful consideration, our request was declined by the ABIM on October 2, 1984.

Although the ABIM clearly took no position on alternatives, they suggested that we examine the model used by geneticists in establishing the American Board of Medical Genetics in 1980. That board, independent of the American Board of Medical Specialties, regularly examines and certifies geneticists.

We understand that the American Board of Medical Genetics, Inc, has been well received and is a widely respected and efficient mechanism for certifying geneticists.

During a very productive meeting on December 8,1984 , the Council on Clinical Pharmacology unanimously agreed to recommend to our three sponsoring societies (ACCP, ASCPT, and ASPET) that we form an independent Board of Clinical Pharmacology to provide a certifying process for qualified clinical pharmacologists.

Subsequently, ACCP, ASCPT, and ASPET each agreed to fully support this recommendation to form an independent board and each society provided "seed" funds to initiate this process.
Several important working groups have been established for the purposes of developing an independent board of clinical pharmacology, developing a certifying examination, and for improving training in clinical pharmacology. The working groups are as follows: "Financial Resources for Establishing "Board"-Drs. Joseph R. Bianchine and Kazuo K. Kimura; "Establishment of a Legal Framework for the "Board"-Drs. Duncan E. Hutcheon, David T. Lowenthal, Joseph R. Bianchine, and Benjamin Calesnick; "Credentialing of Candidates for the Board-Certifying Examination"-Drs. Kazuo K. Kimura, Thomas P. Gibson, Joseph R. DiPalma, and Benjamin Calesnick; "Development of a Board-Certifying Examination"-Drs. Joseph R. DiPalma, W. Leigh Thompson, Harold F. Hailman, Donald S. Robinson, Darrell R. Abernethy, and Alexander Shephard; and "Accreditation of Training Programs"Drs. D. Craig Brater, Terrence F. Blaschke, David T. Lowenthal and Carl C. Peck.

It is anticipated that the first certifying examination administered by the board will be given in the spring of 1987 .

Suggestions, comments, and offering of assistance from interested individuals will be greatly appreciated, especially during the remainder of 1985 , since it is anticipated that the actual formation of this board and the implementation of the certifying process will be accomplished early in 1986.

Membership of the Council on Clinical Pharmacology

Joseph R. Bianchine, MD, PhD Arthur H. Hayes, Jr, MD (Chairman)

Terrence F. Blaschke, MD

D. Craig Brater, $M D$

Benjamin Calesnick, MD

Harold R. Dettelbach, PhD

Joseph R. DiPalma, MD

William Forrest, $M D$

Thomas P. Gibson, MD

Duncan E. Hutcheon, MD

Kazuo K. Kimura, MD, PhD

Louis Lemberger, $M D, P h D$

David T. Lowenthal, MD

Carl C. Peck, MD

W. Leigh Thompson, $M D, P h D$

Richard M. Weinshilboum, MD

Andrew Whelton, MD

Harold F. Hailman, MD, PhD 